Document downloaded from:

http://hdl.handle.net/10251/83163

This paper must be cited as:

Martinez Armero, ME.; Moliner Marin, M.; Sastre Navarro, GI.; Rey Garcia, F.; Martínez, C.; Corma Canós, A. (2016). ITQ-39 zeolite, an efficient catalyst for the conversion of low value naphtha fractions into diesel fuel: The role of pore size on molecular diffusion and reactivity. Journal of Catalysis. 333:127-138. doi:10.1016/j.jcat.2015.10.024

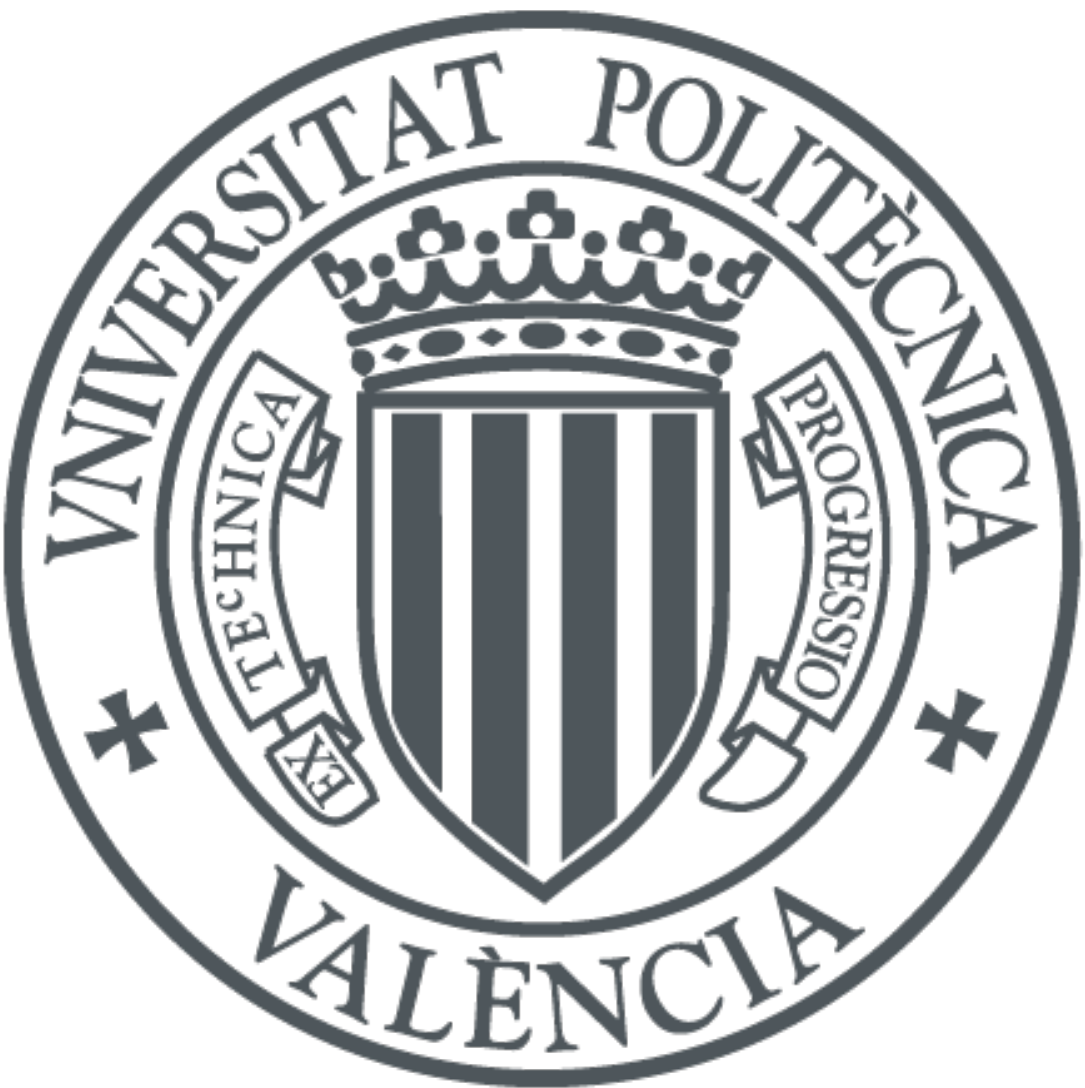

The final publication is available at

http://doi.org/10.1016/j.jcat.2015.10.024

Copyright Elsevier

Additional Information 


\title{
ITQ-39 zeolite, an efficient catalyst for the conversion of low value naphtha fractions into diesel fuel: The role of pore size on molecular diffusion and reactivity.
}

\author{
Marta E. Martínez-Armero, Manuel Moliner, German Sastre, Fernando Rey, Cristina \\ Martínez*, Avelino Corma* \\ Instituto de Tecnología Química (UPV-CSIC), Universidad Politécnica de Valencia, Consejo \\ Superior de Investigaciones Científicas, Valencia, 46022, Spain \\ e-mail: acorma@itq.upv.es,cmsanche@upvnet.upv.es
}

\begin{abstract}
ITQ-39, a multipore zeolite with interconnected 12- and 10-ring channel systems, effectively catalyzes the alkylation of two low value naphtha fractions for the production of diesel range alkylaromatics. A catalytic and molecular dynamics study allows us to conclude that its higher selectivity to the desired diesel fraction and, especially, its longer catalyst life as compared to beta or MCM-22, conventionally used as heterogeneous alkylation catalysts, are due to the combined contribution of its small nano-sized crystallites, moderate Brønsted acidity and unique framework topology.

The small diffusion coefficients obtained for alkylaromatics on ITQ-39 as compared to those corresponding to the large pore beta zeolite evidence the significant diffusional problems of most of the reactants and products through the channels of the ITQ-39 structure. Thus, alkylation reactions on this zeolite seem to occur mainly on the most external acid sites (external surface, pore mouths), whereas the zeolite structure contributes positively by preventing undesired reactions to occur, which would result in lower selectivity to the monoalkylated products and in a faster catalyst deactivation.
\end{abstract}

Keywords: zeolite, ITQ-39, diesel production, naphtha alkylation, catalyst deactivation, diffusion, *-ITN structure 


\section{1.- Introduction}

Future energy supply is a serious concern nowadays, and increasing research efforts are being directed to the development of new technologies allowing the replacement of fossil fuel-based energy by more sustainable sources [1]. However, the major part of energy consumed by the transportation sector is still provided by non-renewable petroleum (96\%) [2] and, while alternative non-fossil-based technologies are developed, it will also be necessary to further optimise well established industrial processes, in order to save fossil resources and extend their lifetime.

Thus, refining and petrochemical industries are forced to adapt their operation schemes to the changing demands. In this line, there is an overproduction of gasoline and a deficiency of diesel nowadays, especially in Europe [3]. An interesting approach to overcome this problem is the conversion of low value naphtha fractions into diesel range fuel by alkylating aromatics with olefins present in the industrial streams. This would result in a double benefit: an increased cetane index of the final aromatic stream, and an increased oxidation resistance of the remaining napththa, due to the reduced olefin content. Aromatic alkylation processes are well known and widely used in industry for the production of petrochemical intermediates, surfactant precursors or synthetic fuels [4]. All these processes take place in the presence of acid catalysts, and the trend is to substitute the traditional inorganic acids or Lewis type of acid catalysts by environmentally friendlier zeolite based catalysts.

Still, very few examples - mostly patents- can be found in the literature related to the use of alkylation processes for upgrading low value naphtha fractions to diesel. Solid acid catalysts have been claimed [5], and among them mono-directional range pore zeolites [5a,d,e] or twoand three-directional zeolites [5c] such as USY, beta, MCM-22, MCM-36, MCM-49 or MCM-56. When production of liquid fuels was the main objective, all these previous studies agree on the improved quality of all the final fractions. Thus, besides the production of a diesel fraction with a cetane index that would, in many cases, allow its direct blending into the diesel pool, the remaining naphthas present lower vapor pressure, lower aromatics and olefins content.

Recently, we have reported the synthesis of ITQ-39, a new zeolite formed by the intergrowth of three different polymorphs giving a three-directional structure with interconnected large and medium pore channels [6]. Zeolites with multidimensional structures are worth to be studied [7], as they may present interesting diffusion and shape selectivity effects.

ITQ-39 showed a good performance in different reactions involving aromatic compounds such as $m$-xylene isomerization and disproportionation, and benzene and toluene alkylation with 
light alcohols [8]. Although its catalytic behavior was closer to that of beta than to ZMS-5, ITQ39 was more para-selective in the isomerization of $m$-xylene gave lower rates of xylene disproportionation as compared to beta. Moreover, during aromatic alkylation, ITQ-39 was much more selective to primary monoalkylated products than beta zeolite, being the proportion of the bulkiest isomers in the dialkylated fraction lower than in the case of beta. Preliminary results on the conversion of low value naphtha fractions into diesel confirmed the suitability of ITQ-39 as aromatic alkylation catalyst, with good activity and stability towards deactivation [6]. The conversion of low value naphtha fractions into diesel fuel is a challenging catalytic process especially regarding catalyst life, as a large number of competing reactions such as olefin oligomerization and olefin or long-chain alkylaromatics cyclization can occur, reactions that may strongly contribute to catalyst deactivation.

Here we present a thorough study on the catalytic behavior of ITQ-39 as compared to that of commercially available zeolites for the production of diesel by alkylation of low value naphtha fractions. ITQ-39 with different Si/Al ratios have been studied, and their activity, selectivity and stability towards deactivation have been correlated with morphological, physico-chemical and acidic properties.

To gain insight into the contribution of the structure of ITQ-39 to its catalytic behavior, a computational molecular diffusivity study of some model molecules, representative of those involved in the naphtha alkylation, within the 10-ring and 12-ring channels of the zeolite has been carried out, where the diffusion of 1-pentene, isopentene, toluene, para-ethyl-toluene, meta-ethyl-toluene, 2-para-tolyl-octane and 2-meta-tolyl-octane in ITQ-39 were simulated using equilibrium molecular dynamics (EMD).

\section{2.- Experimental}

\section{Catalyst preparation}

The zeolites were used in their acid form. As-synthesized ITQ-39 zeolites were prepared with different Si/Al ratios (ranging from 10 to 50 in the final solid) as described in the literature [8], and calcined at $580^{\circ} \mathrm{C}$ for 6 hours in order to remove precluded organic compounds. The commercial beta zeolite (CP811, Zeolyst Inc.) was used without further modification (Beta-13). Zeolites MCM-22 and ITQ-2 were also prepared according to the procedures detailed in the literature [9], and afterwards, calcined at $580^{\circ} \mathrm{C}$ for 6 hours to achieve their acid form.

\section{Catalyst characterization}


Synthesized samples were characterized by powder X-ray diffraction (PXRD) using a multisample Philips X'Pert diffractometer equipped with a graphite monochromator, operating at $45 \mathrm{kV}$ and $40 \mathrm{~mA}$, and using $\mathrm{Cu} \mathrm{KR}$ radiation $(\lambda=0.1542 \mathrm{~nm})$.

The chemical analysis was performed in a 715-ES ICP-Optical Emission spectrometer, after solid dissolution in $\mathrm{HNO}_{3} / \mathrm{HCl} / \mathrm{HF}$ aqueous solution. The organic content of the as-made materials was determined by elemental analysis performed on a SCHN FISONS elemental analyzer. Textural properties were determined by $\mathrm{N}_{2}$ adsorption/desorption isotherms measured on a Micromeritics ASAP 2020 at $77 \mathrm{~K}$.

The relative concentration of acidic sites in the different samples was obtained by FT-IR spectroscopy using pyridine as probe molecule. Pyridine adsorption/desorption experiments were carried out on self-supported wafers $\left(10 \mathrm{mg} \cdot \mathrm{cm}^{-1}\right)$ activated at $673 \mathrm{~K}$ and $10^{2} \mathrm{~Pa}$ for $2 \mathrm{~h}$. After sample activation, pyridine vapor $\left(6.5 .10^{2} \mathrm{~Pa}\right)$ was admitted into the vacuum IR cell and adsorbed onto the zeolite at room temperature. Desorption was performed under vacuum over three consecutive $1 \mathrm{~h}$ periods of heating at 423,523 , and $623 \mathrm{~K}$, each followed by an IR measurement at room temperature. All spectra were scaled according to the sample weight. The amount of Brønsted and Lewis acid sites was determined from the intensities of the bands at ca. 1545 and $1450 \mathrm{~cm}^{-1}$, respectively, using the molar extinction coefficients given by Emeis [10].

\section{Catalytic tests}

Catalytic experiments were performed in an automated high-pressure reaction system equipped with a stainless steel reactor. Alkylation of a straight run naphtha (SRN) with 1octene was done in a 10-mm internal diameter down-flow fixed bed reactor at $453 \mathrm{~K}, 3.5 \mathrm{MPa}$, contact time referred to 1-octene ranging from 0.3 to $1.0 \mathrm{~h}$, and an olefin content of $20 \mathrm{wt} \%$. The catalyst (particle sizes $0.25 \mathrm{~mm}$ and $0.42 \mathrm{~mm}$ ) was diluted in all cases with $\mathrm{SiC}(0.64-0.84$ $\mathrm{mm}$ ) to obtain a bed volume of $4.6 \mathrm{~cm}^{3}$. Production of diesel by alkylation of a straight run naphtha containing aromatics with an olefin rich FCC light naphtha (LN) was carried out in a 14-mm internal diameter down-flow fixed bed reactor at $503 \mathrm{~K}, 3.5 \mathrm{MPa}$, and a contact time, referred to the olefin content of the mixture, of $1.7 \mathrm{~h}$. The feedstock used is a 70:30 (wt:wt) mixture of SRN to FCC naphtha. The composition of the two industrial naphtha streams is given in Table 1. In this case $2.5 \mathrm{~g}$ of catalyst (particle sizes $0.25 \mathrm{~mm}$ and $0.42 \mathrm{~mm}$ ) were diluted in all cases with $\mathrm{SiC}(0.64-0.84 \mathrm{~mm})$ to obtain a bed volume of $7.0 \mathrm{~cm}^{3}$.

The main reaction products were analyzed by gas chromatography. The olefin content at the reactor outlet stream is determined by on-line analysis at various times on stream by means of 
a $30-\mathrm{m} \mathrm{5 \%}$ phenyl-95\% dimethylpolysiloxane column with an internal diameter of $0.25 \mathrm{~mm}$ and a phase film thickness of $1 \mu \mathrm{m}$. In order to quantify the diesel production, simulated distillation of the liquid products was performed by means of a Varian 3800-GC following the ASTM-2887-D procedure. The fractions considered within the C5+ liquids are given in Table 2. Yields to the different fractions were determined in the liquids accumulated in the liquid tramps (as referred to the wt\% olefin in the feed).

\section{Computational methods}

A structural characterization of ITQ-39 has been performed by using lattice energy minimization techniques [11] and the GULP code [12] using a semiempirical shell model forcefield for zeolites containing the $\mathrm{OH}$ group [11b-c] to describe the different silanols. In general, the optimized structures of the three polymorphs of ITQ-39 give geometrical features very close to those found experimentally, with cell parameters within $2 \%$, which is an excellent accuracy. Also $\mathrm{SiO}$ and $\mathrm{SiSi}$ distances, as well as most SiOSi angles, are below $2 \%$ error. $\mathrm{OH}$ stretching frequencies of the silanol groups in the three polymorphs have also been calculated, with all frequencies included in the narrow range $3856-3860 \mathrm{~cm}^{-1}$, which is typical of silanol groups.

We have used equilibrium molecular dynamics (EMD) to simulate the diffusion of 1-pentene, isopentene (3-methyl-1-butene), toluene, para-ethyl-toluene, meta-ethyl-toluene, 2-paratolyl-octane and 2-meta-tolyl-octane in ITQ-39, using the parallel general purpose DL_POLY_2.20 code [13]. The NVE ensemble was used for the EMD calculations (see Supporting Information and Figure S1 for more details). Initial velocities are sampled from a Maxwell-Boltzmann distribution at the state of interest. Simulation cells are created by appropriate scaling of the unit cells, corresponding to a $2 \times 2 \times 1$ supercell of ITQ-39 (polymorph A), containing a composition $416\left(\mathrm{SiO}_{2}\right)+16\left(\mathrm{SiO}_{3 / 2} \mathrm{OH}\right)$, where the latter refers to 16 silanol groups. The velocity-Verlet algorithm is used throughout to integrate the Newton's equations of motion with a timestep of $1 \mathrm{fs}$. The loading is set to mainly 16 molecules, but in some cases the influence of loading has been studied by also considering 8, 12, 24 and 32 molecules in the $2 \times 2 \times 1$ supercell.

Systems sampling the NVE ensemble were simulated at 300, 600 and $900 \mathrm{~K}$. Trajectories were equilibrated for $300 \mathrm{ps}$, time range in which velocities are scaled every $5 \mathrm{fs}$ to the target temperature. Pre-production runs are then initiated up to 500 ps, or until no statistical meaningful variation of total energy was reached. Production runs were initiated from this 
equilibrated system, with simulation times being 50 ns. Such a large simulation time allows obtaining accurate statistics and averages. To make this more computationally feasible the zeolite framework has been kept fixed at the values of the experimental coordinates and cell parameters. Although neglecting the flexibility does not allow obtaining an accurate modellization of the hydrocarbon mobility, especially in the narrower micropores, we have opted by longer simulation times rather than considering zeolite flexibility to study this system. Analysis of the trajectories is carried out from the history files generated, which were saved every picosecond. The main analysis tool used is the Mean Square Displacements (MSD), which is related to the self-diffusion constants, $D$, through the Einstein relation:

6.t. $D=\frac{1}{N_{t}}<\left|r\left(t+t_{0}\right)-r(t)\right|^{2}>$

where $r$ is the guest center of mass position vector, $N_{t}$ is the number of translational degrees of freedom of the guest molecule, and the symbol <> denotes ensemble average.

The forcefield chosen is the so called TraPPE-UA transferable united atom model by Wick et al. [14] which combines a very simple energetic interaction based on pseudoatoms $-\mathrm{CH}_{2}\left(\mathrm{sp}^{2}\right)$, $\mathrm{CH}\left(\mathrm{sp}^{2}\right), \mathrm{C}\left(\mathrm{sp}^{2}\right), \mathrm{CH}(\operatorname{aro}), \mathrm{RC}($ aro $), \mathrm{CH}_{3}\left(\mathrm{sp}^{3}\right), \mathrm{CH}_{2}\left(\mathrm{sp}^{3}\right), \mathrm{CH}\left(\mathrm{sp}^{3}\right)$-, with an accurate simulation of termophysical properties such as critical constants, vapor pressure, heat of vaporization and second virial coefficient. This forcefield considers bonds within a molecule (i.e. it is a molecular mechanics force field), and fixes bond lengths whilst allows mobility of angles and dihedrals. For the mobility of angles, a quadratic function (harmonic) is used, which is an acceptable approximation if angles do not go too far away from the equilibrium values throughout the simulation conditions. Only in the case of aromatic rings, angles are also fixed. For dihedrals, energy terms are based in addition of simple cosine functions which describe properly the conformational changes of the different hydrocarbons. For the interactions between nonbonded pseudoatoms, a typical 12-6 Lennard-Jones potential is used, with a specific parameterization and a spherical truncation enforced for atoms separated longer than $14 \AA$. Finally, given that pseudoatoms do all have the same electronegativity, in this scheme the use of electrostatics is not needed.

\section{3.- Results and discussion}

Zeolite synthesis and characterization.

In this work, the catalytic performance of the ITQ-39 molecular sieve, containing interconnected medium and large pores in its framework, is compared under industrially 
relevant reaction conditions with that of other zeolites commercially used for benzene alkylation such as beta, MCM-22 (MWW) and its delaminated form, ITQ-2.

For this purpose, ITQ-39 zeolites with different $\mathrm{Si} / \mathrm{Al}$ ratios (7 to 50 in the synthesis gel) were synthesized following the procedure described in [8]. As it can be seen in Figure 1, they all show the characteristic PXRD pattern of the ITQ-39 zeolite. Chemical analyses were performed for those ITQ-39 samples, and the Si/Al ratios in the final solids where similar to the theoretical values introduced in the synthesis gels (see Table 3). $\mathrm{N}_{2}$ adsorption reveals that the ITQ-39 sample synthesized with higher Al content presents lower microporosity than the others (see ITQ39-7 in Table 3). The large external surfaces and high mesopore volumes of the ITQ-39 samples are typical of nano-crystalline zeolites. The small size of the ITQ-39 crystals and their aggregation in larger particles was already observed by SEM [8]. The crystallite size and, therefore, the corresponding diffusion path lengths, is expected to have a significant influence when zeolites are used to catalyze processes involving bulky reactants and/or products. This will, probably, be the case of the production of diesel by alkylation of low value naphthas, presented here. Thus, the morphological study has been completed with HR-TEM (see Figure 2), to determine the influence of the chemical composition of ITQ-39 on the crystal size and morphology, and to compare with the other zeolites studied. According to the HR-TEM images, and in good agreement with the external surface area and mesopore volume given in Table 3, sample ITQ39-25 presents the smallest crystallites closely followed by ITQ39-13, being the crystallites of ITQ39-50 larger. The commercial beta zeolite presents also very small crystal size, despite its lower external surface area.

The acidity of ITQ-39 materials was studied by the adsorption/desorption of pyridine followed by IR spectroscopy. These experiments allow the quantification of the Brønsted acid site density and the acid strength of the protons associated to the aluminum atoms present in the zeolite framework. As reported in Table 4, the amount of pyridinium ions remaining (calculated from the $1545 \mathrm{~cm}^{-1}$ band of the IR spectrum using the extinction coefficient given by Emeis [10]) after treatments at $250^{\circ} \mathrm{C}$ or $350^{\circ} \mathrm{C}$ and vacuum (100 Pa), are similar for ITQ-39 samples with Si/Al ratios from 7 to 25 (see results enclosed in Table 4). ITQ-39 sample synthesized with the lowest $\mathrm{Al}$ content ( $\mathrm{Si} / \mathrm{Al}$ ratio of 50 ), clearly shows a higher number of acid sites retaining pyridine at $350^{\circ} \mathrm{C}$ than its ITQ-39 counterparts with higher aluminum content, and also a higher proportion of sites retaining pyridine at high temperature (see the B350/B150 ratio in Table 4). Moreover, ITQ39-50 has the lowest amount of pyridine molecules interacting with Lewis acid (calculated from the $1452 \mathrm{~cm}^{-1}$ band of the IR spectrum), which are associated with extra-framework aluminum atoms (see Table 4). Both facts indicate that the 
reduction of aluminum content in the as-synthesized sample precludes its dealumination, e.g. the formation of octahedral extraframework aluminum species when samples are calcined. As it will be shown later, those acidity differences in the ITQ-39 samples will induce important effects in their catalytic activity.

Together with ITQ-39 materials, two MWW related zeolites were also prepared. On one hand, MCM-22 material, which has a two-dimensional 10-ring pore system containing 12-ring supercages (7.1x18.2 $\AA$ ) only accessible through 10-ring windows [15], was prepared following the procedure described in the literature [9]. The PXRD pattern of the synthesized material corresponds to MCM-22 (see Figure 1), and chemical analyses reveal the same Si/Al ratio in the final solid as the theoretical fraction introduced in its preparation (see Table 3 ). The measured values for the BET surface area and micropore volume of MCM-22 material are $450 \mathrm{~m}^{2} / \mathrm{g}$ and $0.20 \mathrm{~cm}^{3} / \mathrm{g}$, respectively. Moreover, ITQ-2, a delaminated form of MWW with higher external surface was prepared from the lamellar precursor of MCM-22 [9]. This delamination procedure requires the swelling of the layered precursor of MCM-22, followed by delamination by either ultrasounds or fast stirring of the suspension. The delamination degree of swollen MCM-22 precursors is known to depend on their chemical compositions, being favored when decreasing the aluminum content i.e. better delamination degrees are obtained for samples with Si/Al ratios higher than 20 [16]. In this sense, the higher the aluminum content, the higher the charge density, and consequently, stronger interactions between the layers will prevent an extensive delamination [17]. When ITQ-2 is going to be used as a solid acid catalyst, an adequate balance between the number of acid sites (framework Si/Al) and the delamination degree of the final sample has to be reached, and for this reason, we selected the preparation of an ITQ-2 with a Si/Al ratio of 15, even if a full delaminated zeolite would not be achieved when starting with that aluminum content. In this case the reduction of the micropore volume (see Table 3 ) and the changes observed in its PXRD pattern (see Figure 1) when compared to well-defined MCM-22 material, clearly indicate a partial delamination of the sample. Crystal size of the MWW materials is larger than that of ITQ-39 (see Figure 2). Both MCM-22 and ITQ-2 zeolites present Brønsted acid sites able to retain pyridine at the highest desorption temperatures employed (see Table 4), and the total number of these sites is clearly larger than in ITQ-39, independently of the latter's chemical composition.

Finally, a commercial beta zeolite (CP811, Zeolyst Inc.) with similar Si/Al ratio to the MWW materials was characterized in order to compare its physico-chemical properties with those of the synthesized samples. Beta presents higher BET surface area as compared to MCM-22, and values comparable to the ITQ-39 samples with $\mathrm{Si} / \mathrm{Al}$ in the range of 25-50. Its high external 
surface and mesopore volume, although lower than those of ITQ-39, indicate a rather small crystal size, confirmed by HR-TEM (see Figure 2). Thus, regarding textural properties and crystal size, beta shows intermediate values as compared to MCM-22 and ITQ-39. The same is observed for the number of Brønsted acid sites (as measured by pyridine adsorption), which falls between the MWW and the ITQ-39 samples.

\section{Catalytic results}

Zeolite ITQ-39 presents a complex multipore structure, which was recently solved by electron crystallography, directly from the zeolite nanocrystals [6]. The type of pores of ITQ-39 were previously assessed through a series of test reactions [8] using acidic ITQ-39 in specific transformations of the BTX fraction, which can be highly sensitive to the pore dimensions and the presence of channel intersections or lobes in the zeolites. Among the catalytic results presented, gas phase alkylations of benzene and toluene with light alcohols, showed the potential of ITQ-39 as an alkylation catalyst, highly selective to the monoalkylated products when compared to a reference beta zeolite [8]. Moreover, the product distribution obtained evidenced some shape-selectivity, which could be related to a smaller effective pore diameter and lower pore volume as compared to the large pore beta. The structure of ITQ-39 also presents straight pair-wise large pores, resulting in a high density of parallel 12-ring channels along $b[6]$, but with terminal hydroxide groups protruding into one of the 12-ring pairs, this reducing their effective diameter. In any case, the special structural features of ITQ-39 are expected to have an important impact on catalysis, especially when dealing with complex industrial feeds, for which selectivity becomes crucial.

In this section we present the catalytic behavior of ITQ-39 for diesel production by alkylation of straight run naphtha, rich in aromatic compounds, with long chain olefins. In a first set of catalytic experiments, one pure compound, 1-octene, was added to the aromatic straight run naphtha instead of adding the more complex olefinic FCC naphtha stream. The reason for this first, simplified approach is that the olefin rich FCC naphta stream feed contains contaminants (sulfur and nitrogen containing hydrocarbons, see Table 1), which may deactivate the active sites and mask the intrinsic catalytic behavior of ITQ-39 and the rest of the zeolites compared for this reaction. The addition of a pure olefin to the straight run naphtha avoids the negative effect of the poisons, but also simplifies the study from an analytical point of view. Thus, in a first approach ITQ-39 has been compared here for alkylation of the aromatics present in straight run naphtha with 1-octene, with zeolites such as beta or MCM-22, which are reference catalysts. The delaminated ITQ-2, obtained from the laminar MCM-22(P) precursor has been 
included for comparison purposes, since it introduces additional accessibility to larger molecules.

In the second part of the work, we will show that ITQ-39 is also active for catalyzing the alkylation of straight run naphtha with an olefin containing industrial feed such as FCC naphtha, which is the final aim of the proposed process.

\section{- Alkylation of straight run naphtha with 1-octene.}

The olefin conversion at increasing times on stream (TOS) obtained in this set of preliminary alkylation experiments of straight run naphtha with a pure olefin (1-octene) is shown in Figure 3. In order to establish a meaningful comparison with the reference beta $(\mathrm{Si} / \mathrm{Al}=13)$ and $\mathrm{MWW}$ (Si/Al=15) zeolites, an ITQ-39 with $\mathrm{Si} / \mathrm{Al}=13$ (ITQ39-13) was prepared and tested in its acid form. Figure $3 \mathrm{~A}$ shows that, when comparing the catalytic behavior of the different zeolites at a contact time of $1.0 \mathrm{~h}$ referred to the olefin content in the final mixture, zeolite ITQ39-13 is highly active and presents 1-octene conversion values above 98\% (comparable to MCM-22 and ITQ-2), with no appreciable deactivation along the 8 hours on stream. On the other hand beta zeolite, although highly active at short reaction times, already shows some deactivation. To better estimate the catalyst deactivation, results at lower contact time $(0.3 \mathrm{~h})$ were obtained for the conversion of 1-octene with ITQ39-13, MCM-22 and ITQ-2 (Figure 3B). Olefin conversion obtained with beta at a contact time of $0.5 \mathrm{~h}$ is included for comparison purposes. Although ITQ-39 is less active than ITQ-2 under these experimental conditions, the conversion obtained is still comparable to that of MCM-22. However, ITQ-39 is considerably more selective than MCM-22 to diesel range products, and especially to monoalkylated aromatics, as shown in Figure 3C.

When comparing the characterization results obtained in the previous section for ITQ39-13, MCM-22 and beta, it can be seen that they present similar Si/Al ratio, but there are differences regarding their BET specific surface, external surface area and crystal size (Table 3 and Figure 2). Comparing MCM-22 and ITQ-2, with similar specific surface and considerably different external surface (28 and $207 \mathrm{~m}^{2} / \mathrm{g}$ respectively in Table 3), they both present high initial activity ( $\approx 98 \%)$ at $0.3 \mathrm{~h}$ contact time, but ITQ-2, despite its lower acidity, is more stable towards deactivation than MCM-22. The larger external surface area of ITQ-2 is probably the main contributor to the longer catalyst life of ITQ-2. In fact, when MWW materials were studied as catalysts for benzene alkylation with short olefins [18], it was already shown that only the external surface participated in the alkylation reaction, and that the specific topology 
of this external surface was favoring benzene adsorption and further alkylation [19]. Thus, delaminated ITQ-2 was more active than the corresponding MCM-22 zeolite.

Zeolite beta presents high external surface area and mesopore volume due to its small crystallite size, and slightly lower acidity as compared to ITQ-2 (Tables 3 and 4). In zeolite beta the size of the 12-ring pores is expected to allow part of the reaction to occur within the crystalline structure. If we compare the results with those obtained for ITQ-39, with even smaller crystal size (larger BET, micropore and external surface area, and considerably larger mesopore volume) than beta and lower acidity, we can see that the olefin conversion obtained with ITQ-39 is closer to that of the MWW (only external surface contribution) and clearly higher than that of beta, which deactivates much faster than the other zeolites (Figures $3 \mathrm{~A}$ and 3B). On the other hand, results in Table 4 show that beta presents a larger number of total Brønsted acid sites accessible to pyridine. This higher acid site density has been described as beneficial when beta is used as catalyst in the alkylation of benzene with light olefins [4b]. However, naphtha range olefins, such as 1-octene, are more reactive than ethene or propene, and a high number of Brønsted acid sites may result in undesired oligomerization and/or polyalkylation reactions, leading to coke precursors, pore blocking and, eventually, catalyst deactivation. Moreover, beta has also more of those sites capable of retaining pyridine at $350^{\circ} \mathrm{C}$, which may lead to an increase of consecutive reactions, because of stronger adsorption of reactants and products. Thus, the lower acid site density and the lower proportion of sites retaining pyridine at high temperature of ITQ39-13, may be beneficial as it will reduce the extension of secondary alkylations to bulkier hydrocarbons that may foul the micropores. At this point, the lower deactivation rate observed in the case of ITQ-39-13 can be related to its smaller crystals (shorter diffusion paths, larger external surface area) but also to its specific topology.

\section{- $\quad$ Alkylation of straight run naphtha with FCC naphtha.}

Encouraged by the good activity and selectivity results obtained with ITQ-39 during alkylation of straight run naphtha with 1-octene, we proceed to study the catalytic behavior of this zeolite for the alkylation of the straight run naphta (C6-C11) containing aromatics with an olefin rich FCC naphta (C5-C8, see composition in Table 1), and to compare the results with those for the commercial beta zeolite and MWW samples. The reaction was performed at higher temperature $\left(230^{\circ} \mathrm{C}\right)$ and contact time $(1.7 \mathrm{~h})$, to compensate the lower activity of the catalysts when processing these more complex feedstocks. In fact, the presence of compounds different than olefins and aromatics, such as napthenes or sulfur and nitrogen containing 
molecules (see Table 1), will compete and/or deactivate the active sites, reducing in this way the effectiveness of the catalyst.

Figure 4A shows the olefin conversion determined from the on-line analysis of the product stream obtained for the four catalysts. As can be seen there, ITQ-39 with a Si/Al ratio of 13 shows not only a good initial activity but, most importantly, a higher stability against deactivation at increasing TOS when compared to the other zeolites. Thus, the benefits of ITQ39 as catalyst for this process, which could be related to its small crystal size, acidic properties or specific micropore structure, are even larger when dealing with more complex feedstocks. Beta zeolite deactivates very fast, as in the alkylation of the straight run naphtha with 1-octene (see Figure 3A). As discussed above, the higher Brønsted acid site density and the higher proportion of the stronger Brønsted acid sites presented by zeolite beta (see Table 4) may be responsible for the formation of polyalkylated products by secondary alkylation of the primary products, and contribute to foul the micropores. Moreover, the presence of large pore channels present in beta zeolite structure may also favor undesired oligomerization reactions, which lead to deactivation by coke formation. Notice that when processing the industrial feeds, MCM-22 presents a deactivation rate comparable to zeolite beta, and the advantages of delamination become more evident. In fact, ITQ-2 deactivates at a lower rate than bulk MWW (see Figure 4A), as could be expected because of the larger number of external structural "cups", owing to the larger external surface area. It is precisely at these external "cups" where the reaction is taking place [18].

Regarding the formation of alkylated products in the diesel range (C11-C18 and C18-C24 fractions), beta and MCM-22 zeolites show high initial yields after 2 hours (close to $70 \%$ of monoalkylated products, $\mathrm{C} 11-\mathrm{C} 18$, see Figure 4B), that rapidly drops below $40 \%$ after 6 hours. ITQ-2 presents the highest C11-C18 fraction at short times on stream, but it also shows a decrease after 6 hours of reaction (see Figure 4C). On the other hand, ITQ39-13 maintains the initial yields to alkylated products in the diesel ranges, both in C11-C18 and C18-C24 fractions, even after longer TOS (see ITQ39-13 in Figures 4B and 4C). Thus, not only the activity, but also the selectivity to the diesel range products is maintained along the whole TOS range covered in this study.

To discuss the influence of acid site density on activity, selectivity and catalytic deactivation in ITQ-39, samples with different Si/AI ratios have been studied. ITQ-39 materials with Si/Al ratios of $7,13,25$, and 50 (see Table 3 ) were tested for alkylation of heavy naphtha with olefinic light naphtha. 
As observed in Figure 5A, where the evolution of olefin conversion with TOS is represented, ITQ39-7 deactivates faster than the other ITQ-39 samples. This rapid deactivation may be induced by its lower crystallinity (see Table 3). Interestingly, ITQ-39 zeolites with intermediate Si/Al ratios (13-25) present high initial olefin conversions and high stability towards deactivation. ITQ39-13 and ITQ39-25 present almost constant olefin conversions (close to 90\%) along the entire time-on-stream period. Additionally, Figures $5 B$ and $5 C$ shows the high selectivity to alkylated products in the diesel range (C11-C18 and C18-C24 fractions) achieved by ITQ39-13 and ITQ39-25 samples, even after extended reaction times. Finally, ITQ39-50 also deactivates faster as compared to ITQ39-13 and ITQ39-25. This sample synthesized with lower Al content presents lower external surface area as compared to ITQ-39-13 and -25, and significantly lower mesopore volume. This is in good agreement with its larger crystal size, as described in the former section. Taking into account that ITQ39-50 presents a larger number of acid sites, the results obtained clearly point to the critical importance of the external surface area for the catalytic activity and deactivation in the studied reaction.

It has to be remarked that ITQ39-50, with lower external surface as compared to beta and comparable acidic properties, is still much more stable towards deactivation. Thus, besides the clear influence of the external surface area and Brønsted acidity on the catalyst life observed during alkylation of industrial naphtha fractions, the specific structure of ITQ-39 is also playing an important role. Thus, in order to assess the possible effect of the particular ITQ-39 topology on the alkylation of naphtha range aromatics with long chain olefins to produce diesel alkylaromatics, a detailed theoretical molecular diffusivity study of some model molecules involved in this process within the pores of ITQ-39 zeolite has been carried out.

\section{Computational methods}

The main aim is to study if the reactants and products are able to diffuse through the different pores of ITQ-39, especially through the 10-ring pores, which is the role they play during naphtha alkylation or, otherwise, if the catalytic activity has to be related to the high external surface area of these zeolite.

Thus, in the present simulation we have only studied the effect of the micropore structure on the diffusion of reactants and products, and hence we have not included Al (thus Brønsted sites) in the chemical composition.

A view of the channel systems of ITQ-39 is displayed on Figure S2-A enclosed as Supporting Information. 12-ring channels along [010] are straight and their effective diameter is reduced by the presence of the silanol groups which protrude into the channels [6]. The 12-ring 
channels $(4.2 \times 6.6 \AA)$ are crossed perpendicularly by a sinusoidal 10-ring channel (4.2×5.6 $\mathrm{A})$ which runs parallel to [100]. Such sinusoidal channels are composed of two types of 10-rings, indicated by labels ' 1 ' and ' 2 ' in Figure S2-A, which correspond to Figure S2-B, left and center. Finally, a third possibility to exit the 12-ring channel (labeled as ' 3 ' in Figure S2-A) is through another 10-ring (Figure S2-B, right).

- Diffusion of C5 olefins, 1-pentene and isopentene, in ITQ-39.

C5 and C6 olefins are reactants during the naphtha alkylation process, so the rate of diffusion of 1-pentene and isopentene has been firstly studied. In principle the diffusion of 1-pentene was not expected to show pore size restrictions and this small linear molecule should be able to diffuse through both types of 10-ring pores as well as along the 12-ring channel present in ITQ-39. Interestingly, the simulation results presented in Figure 6 show a preferential diffusion of 1-pentene through the 10-ring pores. This could be explained by the contribution of confinement effects, which can increase the diffusivity of a guest molecule when its size gets closer to that of the host channel. In those cases, the micropore acts as a guide for the sorbants' diffusion, and motions perpendicular to the channel direction are largely prevented [20]. On the other hand, diffusion of 1-pentene through the 12-ring cannot be ruled out. Figure 6 shows only the regions of large occupation probability, e.g., the regions where the molecule spends more than $0.3 \%$ of its time, and the trajectories where the molecule spends less than $0.3 \%$ of its time are not represented, trying to visualize only the important regions where the molecule is mainly located. The fact that diffusion of 1-pentene through the 12-rings does not appear is because, according to the results obtained, it spend $0.2 \%$ of its time in the large pore channels, and this indicates that diffusion of the lineal olefin through the 12-ring channels is much slower than through the 10-ring pores. The preferential diffusion of 1-pentene through the medium pore channels when compared with 12-ring pores can also be partly due to restrictions imposed by the silanol groups pointing towards the 12-ring pores which constrain the diffusion through these channels. From the 'xyz' components of the diffusion coefficient given in Table 5 it is seen that the contribution from the 12-ring channel ('y' direction) is the smallest when considering this linear olefin.

The branched isopentene diffuses more slowly than 1-pentene through the 10-ring and through the 12-ring channels, and the main features of this are shown in Figure 7. The discontinuous trajectories of the iso-olefin when its diffusion is simulated along the different 10- and 12-ring channel systems are clearly visible. Thus, mobility of iso-pentene exists but its motion is severely reduced in both, 10- and 12-ring pores. 
The diffusion coefficient corresponding to iso-pentene is around 250 times smaller than that of 1-pentene when calculated at $300 \mathrm{~K}$ (see Table 5). This indicates that whilst linear hydrocarbons do diffuse well, branched hydrocarbons are clearly of similar size to the channels and the diffusivity decreases by two orders of magnitude. Although the 12-ring channels do contain a correspondingly large section in the pore location not intersected by silanol groups, their presence every ca. $12.5 \AA$ (the size of the unit cell across the 'b' parameter) interrupts or slows down the continuous diffusion of molecules, hence leaving all channel systems closer to that of a 10-ring rather than a 12-ring structure, at least when branched hydrocarbons are considered. Thus, regarding the diffusion of iso-olefins, zeolite ITQ-39 presents a behavior more typical of a 10-ring zeolite rather than that of a 12-ring zeolite.

- Diffusion of aromatics, toluene, para- and meta-ethyl-toluene, in ITQ-39.

Toluene, despite its apparently larger size as compared to isopentene, shows higher diffusivity, with its diffusion coefficient being 17 times higher than that of isopentene at $300 \mathrm{~K}$ (see Figure 8 and Table 5). This is due to the fact that diffusion is not only a matter of cross section, but the shapes of the channel and the diffusing molecule will also contribute. In this line, toluene is flat, unlike isopentene, and this is of importance when channels are not circular but elliptical, as in the case of the 12-ring channels of ITQ-39 due to the presence of the silanol groups. Figure S3 shows how the elliptical shape of the 12-rings is more suitable to the passage of toluene as compared to isopentene. In fact, the components of the diffusion coefficients along the three directions (' $x$ ', ' $y$ ' and ' $z$ ' in Table 5) indicate that this molecule diffuses almost indistinctly through the 12- and 10-ring channels.

As shown in Table 5, diffusion is largely enhanced at higher temperatures, with the toluene diffusion coefficient being 5 times larger (at $600 \mathrm{~K}$ ) and 14 times larger (at $900 \mathrm{~K}$ ) than at $300 \mathrm{~K}$. One additional feature of toluene diffusivity is indicated in the movie linked (movie_toluene.mpg) where it can be seen that a large area is covered by the molecule, which besides diffusing through the 10-ring pores spends part of its time jumping from one 12-ring channel to another. The diffusion coefficients at the three temperatures (Table 5) show a larger component of Dy (with respect to Dx and Dz), indicating a larger diffusivity in the 12-ring channels.

Para- and meta-ethyltoluene show a very different behavior. Meta-ethyltoluene shows very low diffusion coefficients at all temperatures (Table 5 ) and this is clearly explained by its bulkier size. Although the size of meta-ethyltoluene could initially seem much larger than that 
of isopentene, they diffuse similarly, with the diffusion coefficients of meta-ethyltoluene being very similar than those of the i-olefin. More surprisingly, para-ethyltoluene diffuses faster than toluene (at $300 \mathrm{~K}$ and $600 \mathrm{~K}$ ), although the differences become less important as the temperature increases. The differences observed for the diffusion of the two aromatics can be explained as follows: toluene fits well within the 12-ring pores, but it does not display a continuous diffusion through this channel. Instead, it jumps in and out from the 10-ring pore system, where diffusion may be slower than in the larger pores. The larger size of paraethyltoluene as compared to toluene, prevents the former to fully enter the 10-ring channels, in which diffusion would be slowed down, and forces this molecule to diffuse preferentially through the 12-ring channel system. This can be clearly seen when comparing Figure 9 with Figure 8 , the former showing a considerably larger motion of para-ethyltoluene than toluene in the 12-ring channels at $300 \mathrm{~K}$ (see movie movie_para_ethyl_toluene.mpg). Thus, the slightly larger diffusion coefficients (especially at lower temperatures) of para-ethyltoluene as compared to toluene, are due to the diffusion of the latter through the 10-ring systems where its motion will become slower until it returns to the 12-ring channels. At the highest temperature studied here $(900 \mathrm{~K})$ it also becomes possible for para-ethyltoluene to enter the 10-ring channels, and hence its diffusivity becomes similar to that of toluene.

- Diffusion of large molecules: 2-para-tolyl-octane and 2-meta-tolyl-octane in ITQ-39.

Considering the alkylation of toluene with n-octene, we have also studied the diffusion in ITQ39 of two possible products, 2-para-tolyl-octane and 2-meta-tolyl-octane (Figure S4). The diffusion coefficients given in Table 5 indicate that none of these molecules shows appreciable diffusion at 300 and $600 \mathrm{~K}$, with diffusion coefficients close or below $10^{-7} \mathrm{~cm}^{2} / \mathrm{s}$, and presenting nearly an order of magnitude increase from 300 to $600 \mathrm{~K}$. At $900 \mathrm{~K}$ a further increase, around 5 times with respect to $600 \mathrm{~K}$, gives diffusion coefficients ca. $5 \times 10^{-7} \mathrm{~cm}^{2} / \mathrm{s}$, which indicate certain mobility, but these only occur at very high temperatures, which are far from the reaction conditions studied in previous sections. Although the diffusion values included in Table 5 show some larger diffusion coefficients for the p-alkylated aromatic, the differences are not big. Figure 10 shows the channel occupancy of 2-para-tolyl-octane in ITQ-39. The diagrams are given at $600 \mathrm{~K}$ in this case, due to the low diffusion presented by this molecule at $300 \mathrm{~K}$. What can be concluded from the simulation results presented in Figure 10 is that, at these temperatures, some diffusion can be observed across all channel systems of ITQ-39. 
An analysis of the diffusional features (see Table 5) confirms that there is no clear preferential diffusion of these products through any of the channel systems, similarly to what was observed in the case of iso-pentene. Moreover, the length of the tolyl-octanes (ca. $11.5 \AA$ ) is commensurate to the distance between the two silanol-silanol neighbors (ca. $12.5 \AA$ ) present in the 12-ring pores, and depending on the orientation of the silanol groups, each product molecule may be interacting with at least one silanol (see Figure S4). This may explain the reduced diffusion coefficients obtained along the 12-ring pore directions, comparable to those obtained along the 10-ring pores. It can also be observed from the data presented in Table 5 that little difference is observed regarding the two loadings considered, which makes sense taking into account that slowly diffusing molecules become more localized, leading to lower intermolecular interactions.

- Overall diffusional features.

The results presented along this section clearly indicate that flat aromatics, such as toluene, are able to diffuse through the 10- and 12-ring channels, whereas small linear olefins will diffuse preferentially through the 10-ring system. However, the absolute values of the diffusion coefficients of toluene, isopentene, $p$ - and $m$-ethyl-toluene at $300 \mathrm{~K}$ and $600 \mathrm{~K}$ (ca. $10^{-7}-10^{-6} \mathrm{~cm}^{2} / \mathrm{s}$ ) are rather small and this can be assessed by calculating the diffusion coefficients of a well-studied molecule, o-xylene, in ITQ-39, ZSM-5 and beta zeolites. In beta zeolite, with the largest channel system and where this molecule is known to diffuse, the diffusion coefficient is $691 \times 10^{-7} \mathrm{~cm}^{2} / \mathrm{s}$ (Table 6), three orders of magnitude larger than that obtained in ITQ-39 $\left(0.63 \times 10^{-7} \mathrm{~cm}^{2} / \mathrm{s}\right)$. The diffusion coefficient of o-xylene in ITQ-39 is only 50 times larger than that of o-xylene in ZSM-5 (Table 6), which is a case of total exclusion. This is suggesting that o-xylene will not diffuse through the channel system of ITQ-39. From the comparison with the diffusion of o-xylene in beta, we may conclude that diffusion coefficients in the order of $10^{-7} \mathrm{~cm}^{2} / \mathrm{s}$ are too low to consider appreciable diffusion. Except 1-pentene, all other diffusion coefficients in ITQ-39 (isopentene, toluene and ethyl-toluenes) show rather low values, $\mathrm{ca} 10^{-7} \mathrm{~cm}^{2} / \mathrm{s}$ at $300 \mathrm{~K}$. Thus, when considering bulkier molecules such as those present in the industrial naphtha streams or formed as alkylation products, we should not expect appreciable diffusion in ITQ-39.

Although the very small crystal size of the ITQ-39 samples described in this study (see Table 3 and Figure 2) will reduce the diffusion path lengths, and this could enhance the intracrystalline diffusion of reactants and products during the alkylation of naphtha fractions, the small diffusion coefficients obtained above for this zeolite suggest that the reactions are taking place mainly on the external surface of the ITQ-39 crystals or very close to the external surface. 
Thus, as in the case of MWW materials, the benefits of ITQ-39 when catalyzing processes involving bulky molecules and/or undesired consecutive and side-reactions may be more related to the structured external surface and the unavailability of the internal pore system.

\section{4.- Conclusions}

The catalytic behavior of zeolite ITQ-39 has been studied and compared with that of other zeolites (beta and MWW-related materials) in naphtha alkylation reactions. Excellent results have been obtained when using ITQ-39 as acid catalyst in the production of diesel range alkylaromatic products with high activity and selectivity to monoalkylated products, together with a lower catalytic deactivation.

The catalytic study shows that the combination of the high external surface of the ITQ-39 samples, due to their nano-sized crystallites, with their moderate Brønsted acidity are responsible for their high activity and selectivity to the desired product fraction, and most importantly, for their lower deactivation rate as compared to well-known alkylation catalysts, such as beta or MCM-22.

The molecular dynamic study shows that linear olefins preferentially diffuse through the 10ring channels of ITQ-39 while isoolefins are strongly limited. Toluene and p-ethyl-toluene only diffuse through the 12-ring channels, though diffusion is very slow. Finally, naphta type alkylation molecules do diffuse extremelly slowly through any of the pore systems (10-rings and 12-rings).

From the diffusion and reactivity studies we conclude that, in the case of naphtha fractions alkylation to diesel range compounds, the transformation of the molecules takes place at the external surface or close to the external surface of the ITQ-39. Nevertheless, the external surface in zeolites is a well-structured surface, which can still play a role on catalytic activity and selectivity, especially when dealing with large molecules.

\section{Acknowledgements}

Financial support by the Spanish Government-MINECO through "Severo Ochoa" (SEV 20120267), Consolider Ingenio 2010-Multicat, MAT2012-37160 and MAT2012-31657 is acknowledged. Repsol is thanked for financial support and permission to publish these results. G. S. thanks ASIC-UPV for computing time. The Electron Microscopy Service of the UPV is acknowledged for their help in samples characterization. 
Table 1: Industrial feeds' composition.

\begin{tabular}{|l|c|c|}
\hline Fraction & Straight Run Naphtha (SRN) & Light FCC Naphtha (LN) \\
\hline n-paraffins & 23.4 & 2.8 \\
\hline i-paraffins & 29.8 & 16.3 \\
\hline Olefins & 0.1 & 45.1 \\
Naphthenes & 33.2 & 15.7 \\
\hline Aromatics & 13.5 & 20.1 \\
\hline Sulfur (ppm) & $<0.5$ & 2100 \\
\hline Nitrogen (ppm) & $<0.5$ & 13 \\
\hline
\end{tabular}


Table 2: Fractions considered within the total $\mathrm{C5}+$ products.

\begin{tabular}{|c|c|c|}
\hline Fraction & Carbon number range & Temperature range \\
\hline NAPHTHA & C5-C11 & $<196.1^{\circ} \mathrm{C}$ \\
\hline G1 (mono-alkylated) & C11-C18 & 196.1-316.1으 \\
\hline G2 (di-alkylated) & $\mathrm{C} 18-\mathrm{C} 24$ & $316.1-391.190 \mathrm{C}$ \\
\hline G3 (heavy ends) & $\mathrm{C} 24+$ & $>391.19 \mathrm{C}$ \\
\hline
\end{tabular}


Table 3: Physico-chemical properties of reference and ITQ-39 samples used in this study.

\begin{tabular}{l|ccccccc}
\hline Sample & $(\mathrm{Si} / \mathrm{Al})_{\mathrm{gel}}$ & $(\mathrm{Si} / \mathrm{Al})_{\text {ICP }}$ & $\begin{array}{c}\mathrm{BET} \\
\left(\mathrm{m}^{2} / \mathrm{g}\right)\end{array}$ & $\begin{array}{c}\mathrm{S}_{\text {micro }} \\
\left(\mathrm{cm}^{2} / \mathrm{g}\right)\end{array}$ & $\begin{array}{c}\mathrm{S}_{\text {ext }} \\
\left(\mathrm{cm}^{2} / \mathrm{g}\right)\end{array}$ & $\begin{array}{c}\mathrm{V}_{\text {micro }}{ }^{\mathrm{a}} \\
\left(\mathrm{cm}^{3} / \mathrm{g}\right)\end{array}$ & $\begin{array}{c}\mathrm{V}_{\text {meso }} \\
\left(\mathrm{cm}^{3} / \mathrm{g}\right)\end{array}$ \\
\hline MCM-22 & 15 & 15 & 450 & 422 & 28 & 0.201 & 0.147 \\
ITQ-2 & 15 & 15 & 507 & 300 & 207 & 0.150 & 0.280 \\
\hline Beta-13 & -- & 13 & 580 & 378 & 203 & 0.183 & 0.302 \\
\hline ITQ39-7 & 7 & 10 & 459 & 165 & 294 & 0.074 & 0.393 \\
ITQ39-13 & 13 & 13 & 662 & 422 & 240 & 0.200 & 0.399 \\
ITQ39-25 & 25 & 22 & 595 & 336 & 258 & 0.156 & 0.489 \\
ITQ39-50 & 50 & 32 & 573 & 420 & 153 & 0.200 & 0.239 \\
\hline
\end{tabular}

a. Micropore volume obtained from t-plot

b. As determined from BJH adsorption pore distribution 
Table 4: Acidity of reference and ITQ-39 samples used in this study as determined by FT-IR combined with pyridine adsorption-desorption.

\begin{tabular}{|c|c|c|c|c|c|c|c|}
\hline \multirow{3}{*}{ Catalyst } & \multicolumn{7}{|c|}{ Acidity ( $\mu \mathrm{mol}$ pyridine/g) } \\
\hline & \multicolumn{4}{|c|}{ Brønsted sites } & \multicolumn{3}{|c|}{ Lewis sites } \\
\hline & $\mathrm{T}=150^{\circ} \mathrm{C}$ & $\mathrm{T}=250^{\circ} \mathrm{C}$ & $\mathrm{T}=350^{\circ} \mathrm{C}$ & B350/B150 & $\mathrm{T}=150^{\circ} \mathrm{C}$ & $\mathrm{T}=250^{\circ} \mathrm{C}$ & $T=350 \circ C$ \\
\hline MCM-22 & 323 & 293 & 196 & 0.61 & 94 & 81 & 94 \\
\hline ITQ-2 & 235 & 194 & 86 & 0.37 & 111 & 91 & 84 \\
\hline Beta-13 & 202 & 140 & 62 & 0.31 & 220 & 212 & 185 \\
\hline ITQ39-7 & 170 & 60 & 15 & 0.09 & 292 & 210 & 166 \\
\hline ITQ39-13 & 121 & 51 & 22 & 0.18 & 239 & 194 & 184 \\
\hline ITQ39-25 & 94 & 64 & 31 & 0.32 & 208 & 196 & 188 \\
\hline ITQ39-50 & 154 & 131 & 71 & 0.46 & 92 & 94 & 91 \\
\hline
\end{tabular}


Table 5: Diffusion coefficients $\left(10^{-7} \mathrm{~cm}^{2} / \mathrm{s}\right)$ of different hydrocarbons in ITQ-39. Loadings refer to a $2 \times 2 \times 1$ supercell of ITQ-39, with composition $416\left(\mathrm{SiO}_{2}\right)+16\left(\mathrm{SiO}_{3 / 2} \mathrm{OH}\right)$. ).

\begin{tabular}{|c|c|c|c|c|c|c|}
\hline Temperature & & $300 \mathrm{~K}$ & & $600 \mathrm{~K}$ & \multicolumn{2}{|c|}{$900 \mathrm{~K}$} \\
\hline Loading & & 16 & & 16 & \multicolumn{2}{|c|}{16} \\
\hline 1-pentene & & 118 & & 286 & \multicolumn{2}{|c|}{341} \\
\hline$D(x, y, z)$ & & $(70,24,24)$ & & $(168,63,55)$ & \multicolumn{2}{|c|}{$(194,53,94)$} \\
\hline isopentene & & 0.5 & & 7 & \multicolumn{2}{|c|}{20} \\
\hline$D(x, y, z)$ & & $(0.2,0.2,0.1)$ & & $(2.5,3,1.5)$ & \multicolumn{2}{|c|}{$(5,11,4)$} \\
\hline toluene & & 7 & & 37 & \multicolumn{2}{|c|}{100} \\
\hline$D(x, y, z)$ & & $(0.5,6,0.5)$ & & $(11,19,7)$ & \multicolumn{2}{|c|}{$(36,48,16)$} \\
\hline$p$-ethyl-toluene & & 19 & & 55 & \multicolumn{2}{|c|}{101} \\
\hline$D(x, y, z)$ & & $(2.4,16,0.6)$ & & $(10,38,7)$ & \multicolumn{2}{|c|}{$(17,79,5)$} \\
\hline$m$-ethyl-toluene & & 0.5 & & 9 & \multicolumn{2}{|c|}{30} \\
\hline$D(x, y, z)$ & & $(0.2,0.1,0.2)$ & & $(3,3,3)$ & \multicolumn{2}{|c|}{$(10,10,10)$} \\
\hline Temperature & \multicolumn{2}{|c|}{$300 \mathrm{~K}$} & \multicolumn{2}{|r|}{$600 \mathrm{~K}$} & \multicolumn{2}{|c|}{$900 \mathrm{~K}$} \\
\hline Loading & 8 & 12 & 8 & 12 & 8 & 12 \\
\hline 2-meta-tolyl-octane & 0.02 & 0.03 & 0.58 & 0.59 & 5.77 & 3.62 \\
\hline 2-para-tolyl-octane & 0.09 & 0.23 & 1.23 & 1.17 & 4.87 & 4.12 \\
\hline
\end{tabular}


Table 6: Diffusion coefficients $\left(10^{-7} \mathrm{~cm}^{2} / \mathrm{s}\right)$ of ortho-xylene in pure silica beta, ZSM-5 and ITQ39.

\begin{tabular}{lccc}
\hline Temperature & $300 \mathrm{~K}$ & $600 \mathrm{~K}$ & $900 \mathrm{~K}$ \\
\hline o-xylene in beta & 691 & 1260 & 1202 \\
o-xylene in ZSM-5 & 0.013 & 0.078 & 0.185 \\
o-xylene in ITQ-39 & 0.63 & 5.49 & 14.47 \\
\hline
\end{tabular}




\section{Figure Captions}

Figure 1: XRD patterns of the synthesized samples

Figure 2: HR-TEM images of ITQ39-13 (A), ITQ39-25 (B), ITQ-39-50 (C) and commercial beta CP811 (D).

Figure 3: Olefin conversion obtained at contact times $(\tau)$ of $1.0 \mathrm{~h}(\mathrm{~A})$ and $0.3 \mathrm{~h}(\mathrm{~B})$, selectivity to diesel (C11-C24) in C11+ (B), and selectivity to mono-alkylated aromatics in diesel (C) obtained with ITQ-39 and reference beta and MWW zeolites in alkylation of a straight run naphtha with 1-octene at $180^{\circ} \mathrm{C}$ and $2.5 \mathrm{MPa}$. Contact time for beta in $(\mathrm{B})$ is $0.5 \mathrm{~h}$.

Figure 4: Olefin conversion $(A)$ determined on-line and yield to the different fractions in the liquid product accumulated between 2-4 (B) and 6-8 (C) hours of reaction obtained for ITQ-39, reference beta and MWW zeolites of similar composition in alkylation of straight run naphtha with FCC naphtha. $\mathrm{T}=230 \mathrm{\circ} C, \mathrm{P}=3.5 \mathrm{MPa}, \tau=1.7 \mathrm{~h}$.

Figure 5: Olefin conversion $(A)$ determined on-line and yield to the different fractions in the liquid product accumulated between 2-4 (B) and 6-8 (C) hours of reaction obtained for ITQ-39 zeolites with different Si/Al ratio in alkylation of a straight run naphtha with a FCC naphtha. $\mathrm{T}=230$ 으, $\mathrm{P}=3.5 \mathrm{MPa}, \tau=1.7 \mathrm{~h}$.

Figure 6: Occupational density (isovalue=0.003) of 1-pentene at $300 \mathrm{~K}$ in ITQ-39. Top view: main diffusion across the sinusoidal 10-ring channels. Bottom view: no diffusion across the 12ring, parallel to ' $b$ ' axis, is observed. Only the regions of largest molecular population, where the molecule spends more than $0.3 \%$ of its time, are plotted.

Figure 7: Occupational density (isovalue=0.003) of iso-pentene at $300 \mathrm{~K}$ in ITQ-39. Top view: main diffusion across the sinusoidal 10-ring channels. Bottom view: diffusion across the 12ring, parallel to ' $b$ ' axis. Only the regions of largest molecular population, where the molecule spends more than $0.3 \%$ of its time, are plotted.

Figure 8: Occupational density (isovalue=0.003) of toluene at $300 \mathrm{~K}$ in ITQ-39. Diffusion across the 12-ring, parallel to 'b' axis, is observed. Only the regions of largest molecular population, where the molecule spends more than $0.3 \%$ of its time, are plotted.

Figure 9: Occupational density (isovalue=0.003) of para-ethyltoluene at $300 \mathrm{~K}$ in ITQ-39. More marked diffusion across the 12-ring, parallel to 'b' axis, than in the case of toluene (Figure 9), is observed. Only the regions of largest molecular population, where the molecule spends more than $0.3 \%$ of its time, are plotted. 
Figure 10: Occupational density (isovalue $=0.003$ ) of 2-para-tolyl-octane at $600 \mathrm{~K}$ in ITQ-39. Top view: main diffusion across the sinusoidal 10-ring channels. Bottom view: diffusion across the 12-ring (parallel to ' $b$ ' axis). Only the regions of largest molecular population, where the molecule spends more than $0.3 \%$ of its time, are plotted. 
Figure 1:

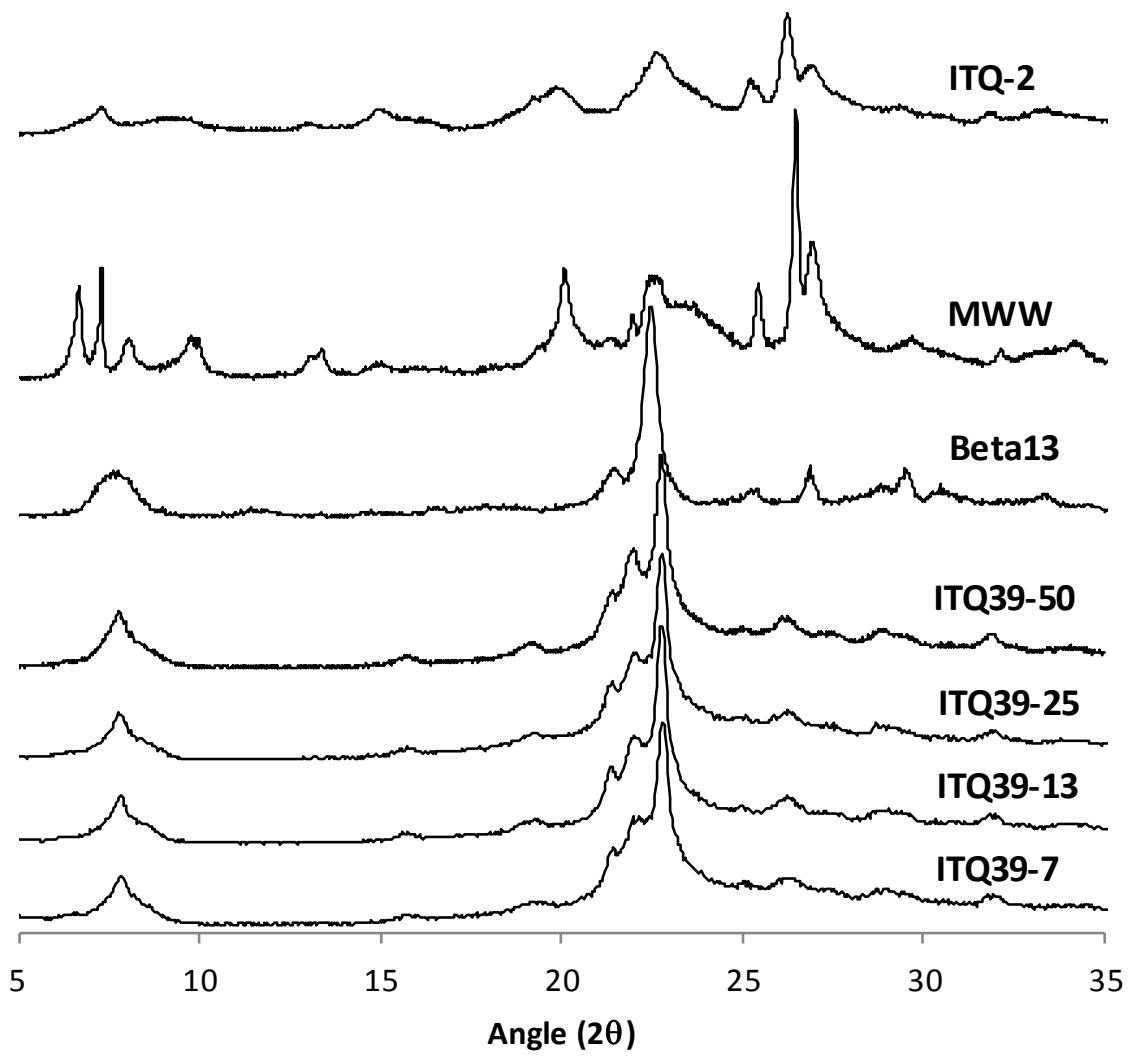


Figure 2:
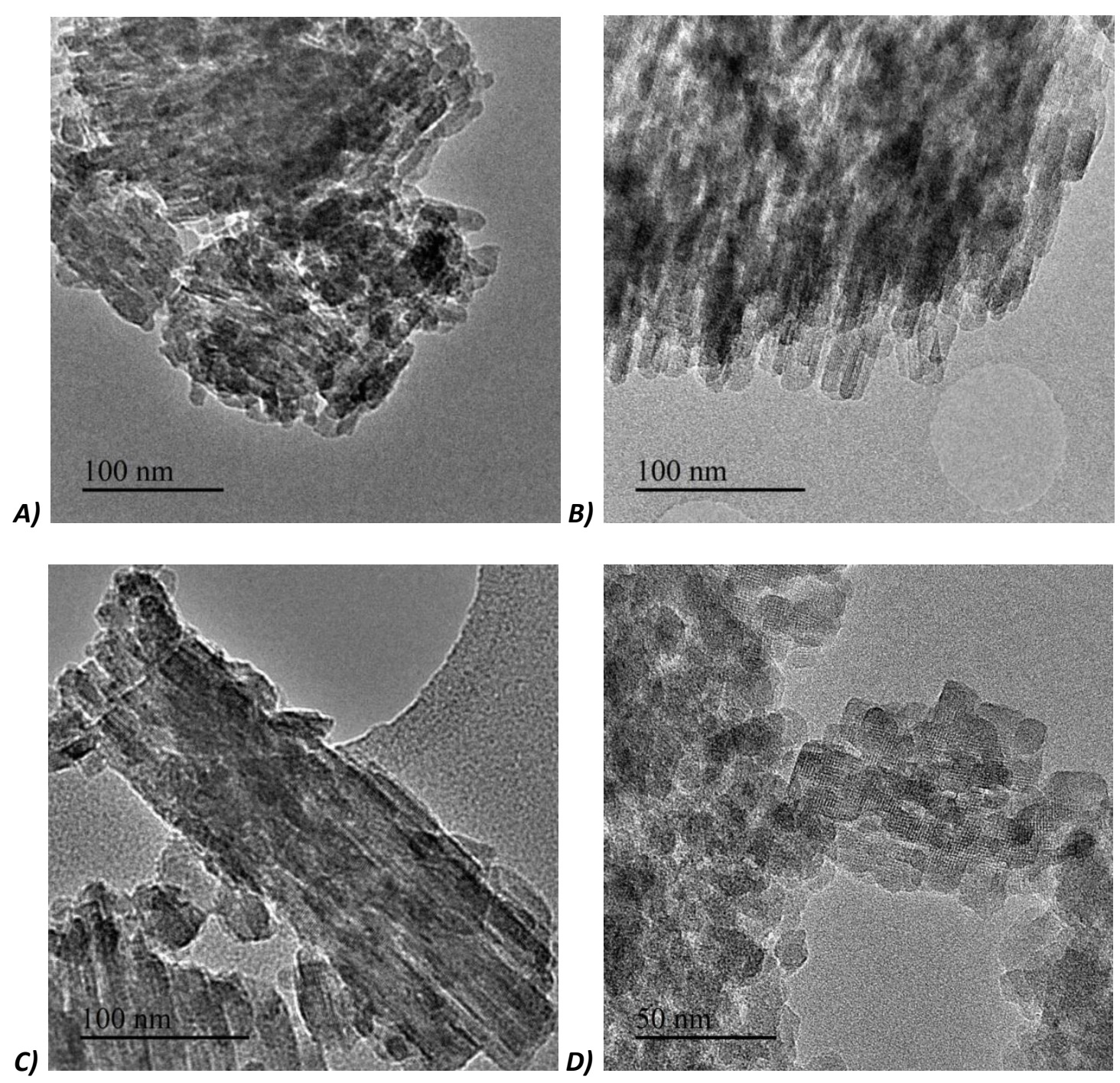
Figure 3:
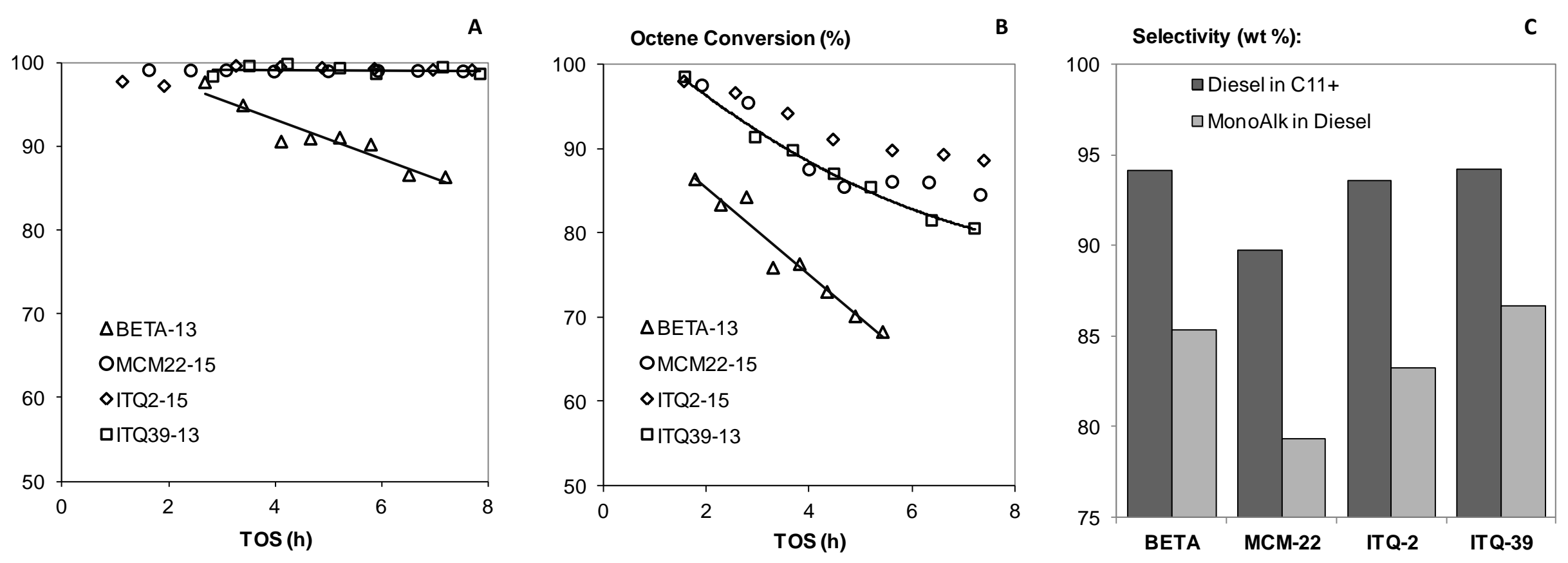


\section{Figure 4:}
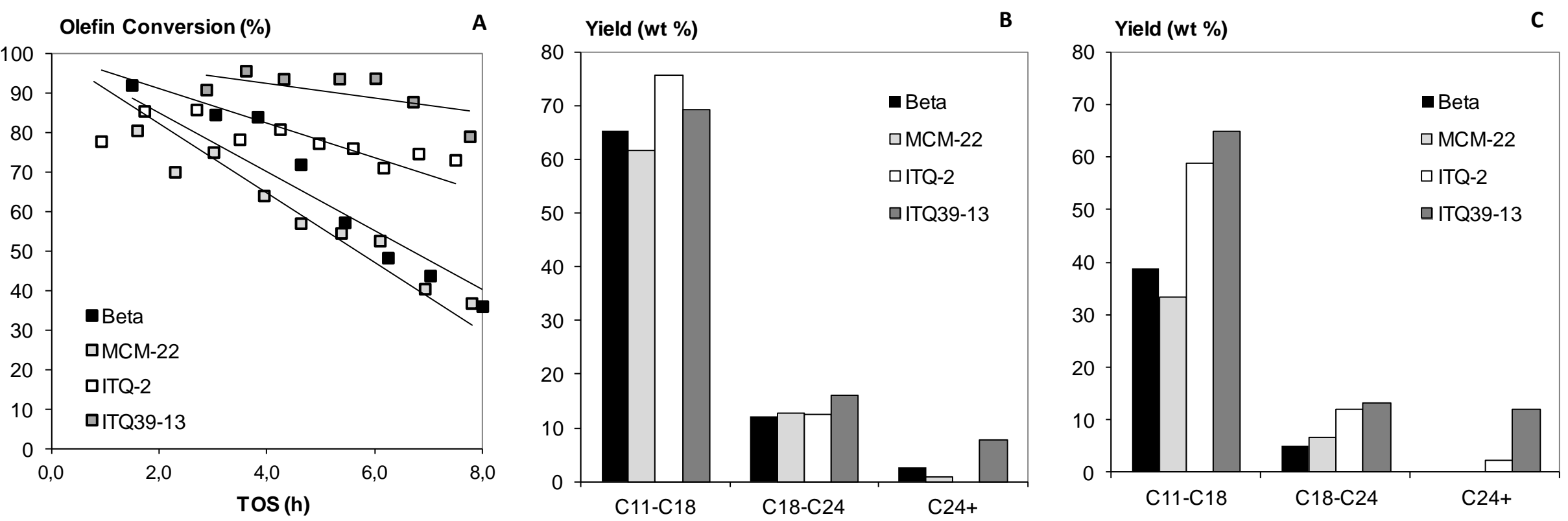
Figure 5:
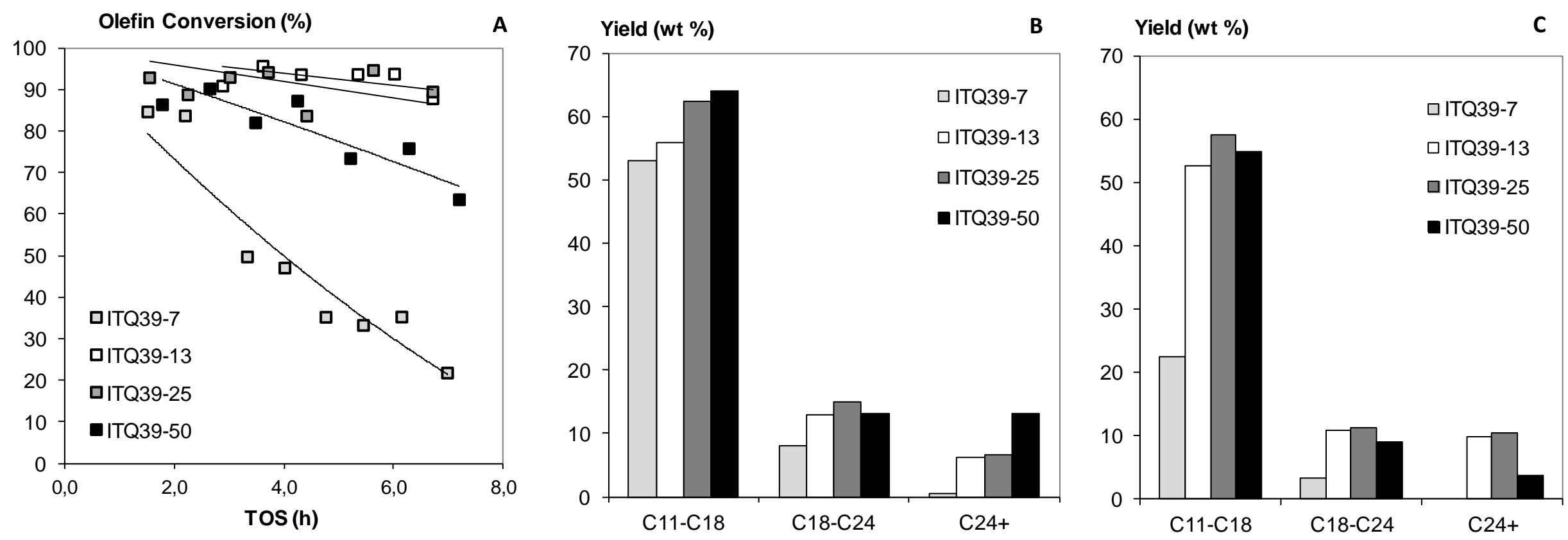
Figure 6:
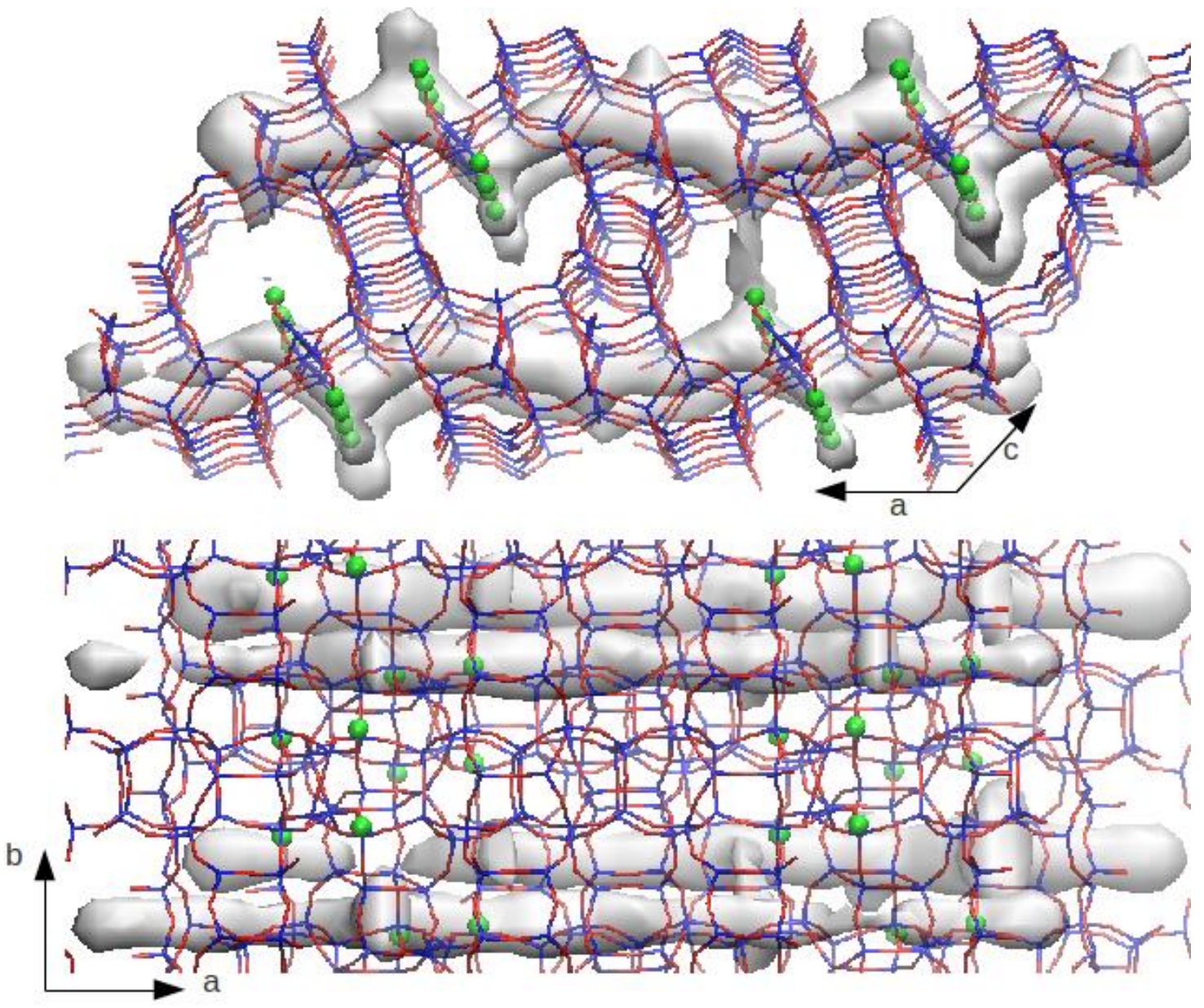
Figure 7:

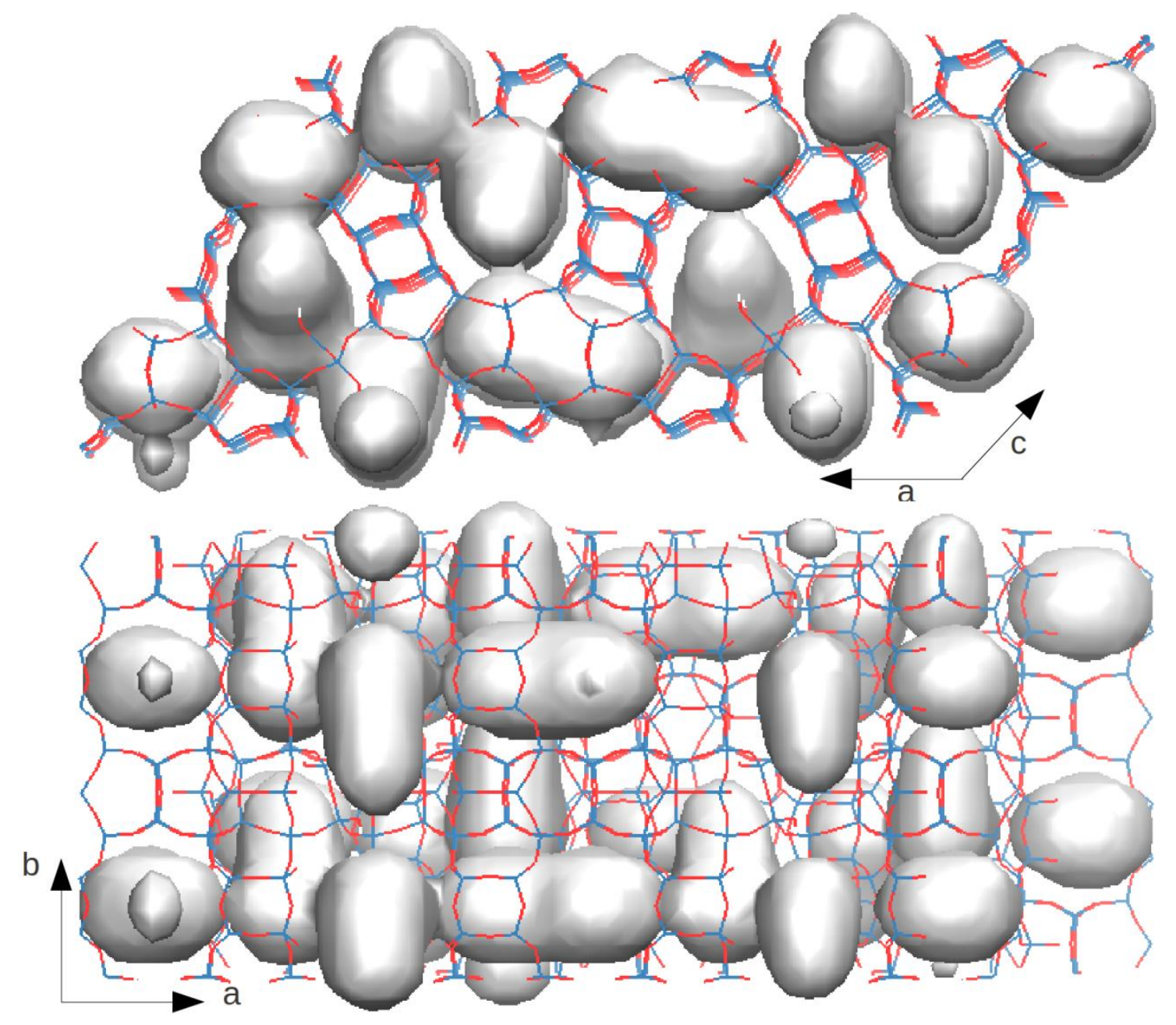


Figure 8:

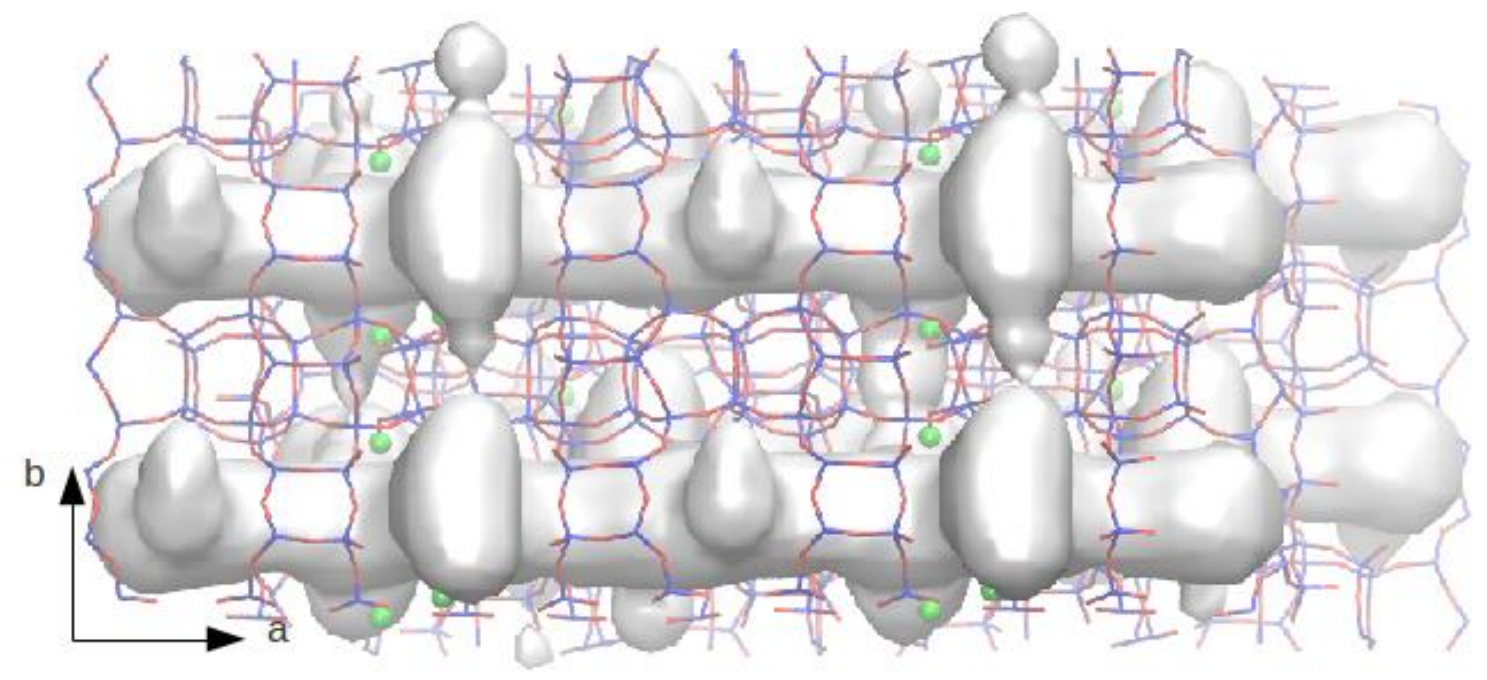


Figure 9.

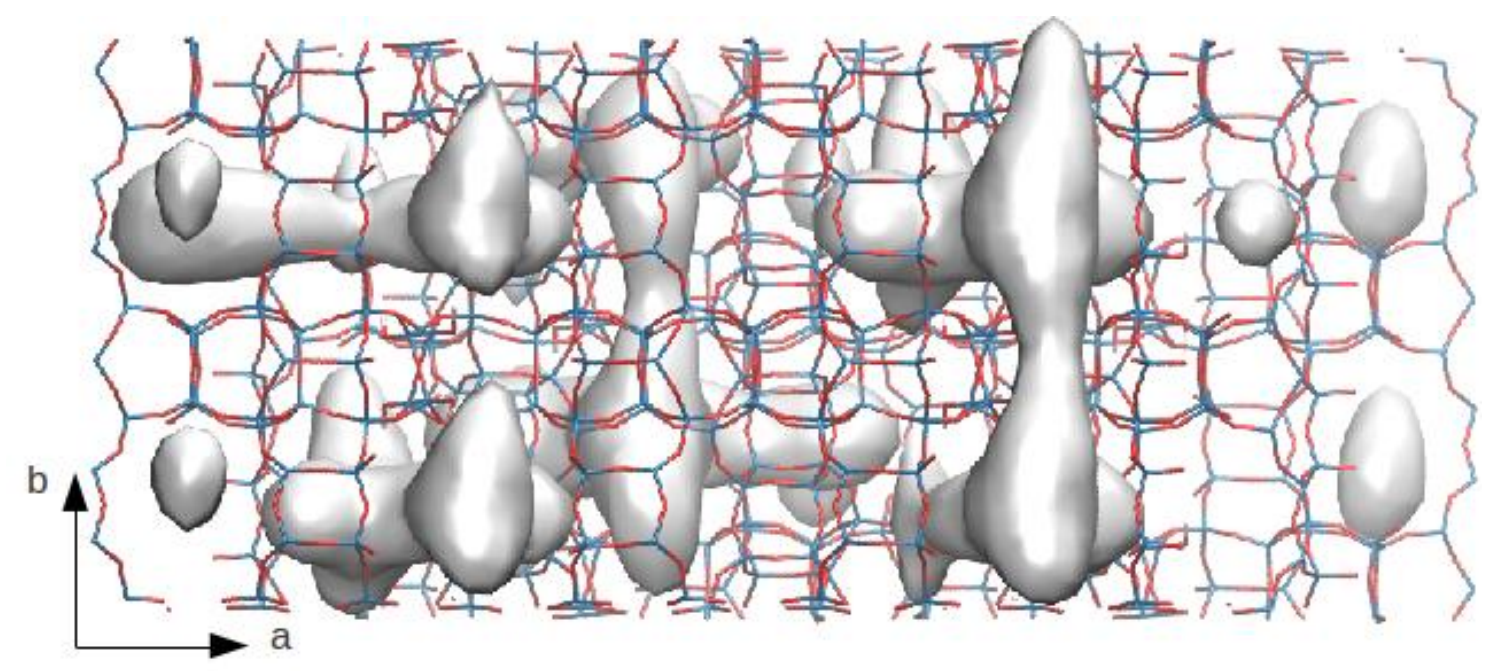


Figure 10:

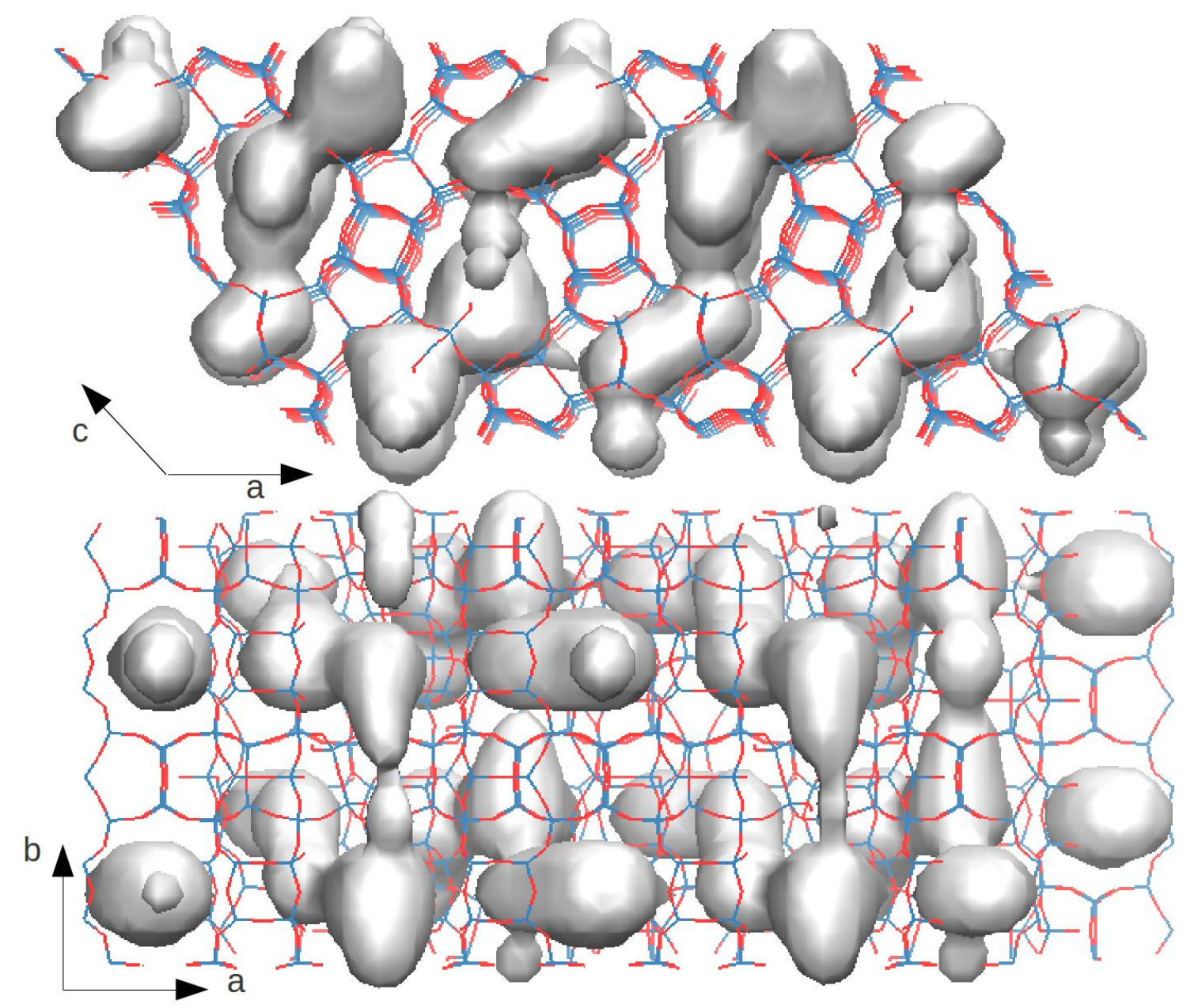




\section{References:}

[1] (a) G.W. Huber, S. Iborra, A. Corma, Chem. Rev. 106 (2006) 4044; (b) D.A. Wood, C. Nwaoha, B.F. Towler, J. Nat. Gas Sci. Eng. 9 (2012) 196.

[2] Key World Energy Statistics (2010).

[3] European Refining Markets: Adapting to overcapacity, remaining competitive. 4th Annual European Refining Markets, Brussels, Belgium, September 27-28 (2010).

[4] (a) T.F. Dignan Jr., C. Morris Smith, C.R. Venkat, Appl. Catal. A-Gen. 221 (2001) 283; (b) C. Perego, P. Ingallina, Catal. Today. 73 (2002) 3; (c) S.I. Hommeltoft, Appl. Catal. A-Gen. 221 (2001) 421; (d) A. Corma, A. Martínez, Catal. Rev. 35 (1993) 483; (e) B.D. Alexander, G.A. Huff, V.R. Pradhan, W.J. Reagan, R.H. Cayton, US A 6024865 (2000); (f) M. Hodges, G. Ketley, WO A2 2003035808 (2003); (g) G.F. Stuntz, WO A1 2005019387 (2005).

[5] (a) S.A. Tabak, US Patent 4594143 (1986); (b) N.Y. Chen, B.K. Huh, A.B. Ketkar, C. Venkat, US Patent 4871444 (1989); (c) N.A. Collins, M.E. Landis, H.K.C. Timken, J.C. Trewella, WO 00/39253 (2000); (d) R.A. Ludolph, F.F. Cooper, EP 0780458 A2 (1997); (e) D.S. Connor, US 2005/0027148 A1 (2005).

[6] (a) T. Willhammar, J. Sun, W. Wan, P. Oleynikov, D. Zhang, X. Zou, M. Moliner, J. Gonzalez, C. Martínez, F. Rey, A. Corma, Nat. Chem. 4 (2012) 188; (b) M. Moliner, A. Corma, Micropor. Mesopor. Mater. 164 (2012) 44.

[7]M. Moliner, C. Martínez, A. Corma, Angew. Chem. Int. Ed. 54 (2015) 3560.

[8] M. Moliner, J. González, M.T. Portilla, T. Willhammar, F. Rey, F.J. Llopis, X. Zou, A. Corma, J. Am. Chem. Soc. 133 (2011) 9497.

[9] (a) A. Corma, C. Corell, J. Perez-Pariente, Zeolites 15 (1995) 2; (b) A. Corma, V. Fornes, S.B. Pergher, Th.L.M. Maesen, J.G. Buglass, Nature 396 (1998) 353.

[10] C. A. Emeis, J. Catal. 141 (1993) 347.

[11] (a) Computer Simulation of Solids, Eds. C.R.A. Catlow, W.C. Mackrodt; IEcture Notes in Physics, Vol. 166, Springer, Berlin, 1982; (b) C.R.A. Catlow, A.N. Cormack, Int. Rev. Phys. Chem. 6 (1987) 227; (c) K.P. Schroder, J. Sauer, M. Leslie, C.R.A. Catlow, J.M. Thomas, Chem. Phys. Lett. 188 (1992) 320.

[12] (a) J.D. Gale, J. Chem. Soc. Faraday Trans. 93 (1997) 629; (b) J.D. Gale, A.L. Rohl, Mol. Simul. 29 (2003) 291.

[13] DL_POLY_2.0 User Manual; Forester, T. R.; Smith, W. CCLRC Daresbury Laboratory, 1995.

[14] C.D. Wick, M.G. Martin, J.I. Siepmann, J. Phys. Chem. B. 104 (2000) 8008.

[15] M.E. Leonowicz, J.A. Lawton, S.L. Lawton, M.K. Rubin, Science 264 (1994) 1910.

[16] V. Ayala, A. Corma, M. Iglesias, J.A. Rincon, F. Sanchez, J. Catal. 224 (2004) 170.

[17] P. Frontera, F. Testa, R. Aiello, S. Candamano , J.B. Nagy, Micropor. Mesopor. Mater. 106 (2007) 107.

[18] A. Corma, V. Martínez-Soria, E. Schnoeveld, J. Catal. 192 (2000) 163.

[19] G. Sastre, C.R.A. Catlow, A. Corma, J. Phys. Chem. B 103 (1999) 5187.

[20] (a) E.G. Derouane, J.-M. André, A.A. Lucas, J. Catal. 110 (1988) 58; (b) G. Sastre, A. Corma, J. Mol. Catal. A 305 (2009) 3. 